4 Marcus DM, Latov N, Hsi BP, Gillard BK. Measurement significance of antibodies against $\mathrm{G}_{\mathrm{m}}$ ganglioside. F Neuroimmunol 1989;25:155-9.

5 Bradley WG. Critical review of gangliosides and thyrotropin-releasing hormone in peripheral neuromuscular diseases. Muscle and Nerve 1990;13:833-42.

6 Sautter J, Schwartz M, Duvdevani R, Sabel BA. GMI ganglioside treatment reduces visual deficits fter graded rush of the rat optic nerve. Brain Res 1991;565:23-33.

7 Geisler FH, Dorsey FC, Coleman WP. Recovery of motor function after spinal cord injury, randomized placebo controlled trial with GM1 gangliosides. N Engl f Med 1991;324:1829-38.

8 Schneider JS, Pope A, Simpson K, Taggart J, Smith MG, DiStefano L. Recovery from experimental parkinsonism in primates with $\mathrm{G}_{\mathrm{M} 1}$ ganglioside treatment. Science 1992;256:843-6.
9 Ramirez JJ, Sabel BA. Toward a unified theory of ganglioside mediated functional restoration after brain injury: lesion size, not lesion site, is the primary factor determing efficacy. Acta Neurobiol 1990;50:415-38.

10 Sabel BA. Gangliosides and brain repair. Neuroscience Facts 1992;3:83-4.

11 Figeuras A, Morales-Olivas FJ, Capella D, Palop V, Laporte J-R. Bovine gangliosides and acute motor polyneuropathy. BMF 1992;305:1330-1.

12 Nagai $Y$, Momoi T, Saito M, Mitsuzawa E, Ohtani S. Ganglioside syndrome, a new autoimmune neurologic disorder, experimentally induced with brain gangliosides. Neurosci Lett 1976;2 $107-11$

\title{
The patient's charter and the triage nurse
}

\section{Done properly, nurse triage can halve waiting times in $A \mathcal{E} E$}

Standards set in the patient's charter for waiting times in accident and emergency departments have put the role of the triage nurse under the spotlight. The standard "You will be seen immediately and your need for treatment assessed"1 covers the traditional function of triage (from the French, sorting out). This includes assessing patients, providing first aid, deciding priorities, controlling the flow of patients, initiating diagnostic procedures, and liaising with other health care professionals and relatives. ${ }^{2-7}$ None of this is new, but the effectiveness of triage nurses has recently been challenged. ${ }^{8}$

Although there are contrary findings, research has shown that a system of nurse triage can significantly reduce waiting times when performed effectively. ${ }^{9}$ Studies that have not shown this, such as one by George et al, ${ }^{8}$ have been based on a narrow definition of nurse triage and have not included other factors important to an effective system, such as staffing and departmental layout.

The whole system within which nurse triage operates is crucial to its success. Slater has shown the benefits of having two triage nurses, one for seriously ill and one for ambulant patients, each seeing patients in different areas. This method halves the waiting times for acutely ill patients. ${ }^{10}$ Shields also suggested that ambulant patients should be seen in a separate area from the acutely ill; again treatment delays were halved. ${ }^{11}$ Separating out patients without acute problems improves the use of emergency facilities and staff. Debates continue over whether nurse triage needs to operate throughout the whole day to improve waiting times or whether it works when used only for short periods.

Clearly the workload of the department, its layout, the amount of major trauma, and seasonal peaks and troughs all affect the number of nurses needed for triage. Education is also crucial for the success of the system, and proper preparation of the triage nurse must be built into the implementation and continuing evaluation of the system. Nuttall suggested that training should include a period of observation and practical experience under the direction of an experienced triage nurse. ${ }^{9}$

Nurse triage seems the preferred way of addressing the standard on immediate assessment for the patient's charter. The effectiveness of the delivery of any standard needs to be evaluated by well structured, valid, and reliable studies. Those studies that have met these criteria suggest that nurse triage is effective. Importantly, nurse triage seems to increase patients' satisfaction as well.

TOM KEIGHLEY Director of Nursing and Quality

JAN MAYCOCK Acting Assistant Regional Director (Quality)

Yorkshire Regional Health Authority, Harrogate HG1 5AH

1 Department of Health. The patient's charter. London: DoH, 1992.

Mallett J. Triage in accident and emergency departments. Fournal of Advanced Nursing 1992;15:1443-51.

3 Bailey A, Hallam K, Hirst K. Triage on trial. Nursing Times 1987;83:65-6.

4 Buckles E. Advanced trauma life support. Nursing Standard 1990;4:54-5.

5 Carew-McColl M, Buckles E. A workload shared. Health Service fournal 1990;100:27.

6 Harris B, Fox J. Eye opener at Bristol. Health Service fournal 1986;96:364-5.

7 Jones G. Top priority. Nursing Standard 1988,3:28.9.

7 Jones G. Top priority. Nursing Standard 1988;3:28-9. a British accident and emergency department. BMf 1992;304:876-8.

a British accident and emergency department. BMF 1992;304:8
Nuttall $M$. The chaos controller. Nursing Times 1982:20:656-8.

10 Slater R. Triage nurse in the emergency department. American fournal of Nursing 1970;70:127-9.

10 Slater R. Triage nurse in the emergency department. American foumal of Nursing 1970;70:127-9. Nursing 1976;2:37-41. 